\title{
Deformities of cerebral palsy treated by ilizarov technique
}

\begin{abstract}
Cerebral palsy is a condition that affects thousands of babies and children each year. It is not contagious, which means no one can catch it from anyone who has it. The word cerebral means having to do with the brain. The word palsy means a weakness or problem in the way a person moves or positions his or her body. A kid with Cerebral palsy (CP) has trouble controlling the muscles of the body (hall mark of the condition is motor dysfunction, i.e. there is abnormal muscle tone, abnormal posture and movement). ${ }^{1,2}$ Normally, the brain tells the rest of the body exactly what to do and when to do it. But because CP affects the brain, depending on what part of the brain is affected, a kid might not be able to walk, talk, eat or play the way most kids do. It is a non-progressive but often changing motor impairment syndromes. It is usually secondary to an insult of limited duration or anomalies of the brain arising in the early stages of development. (Viz. prenatal, intranatal, neonatal and post natal up to 5 years). The changing clinical picture results from developmental maturation and intervention. The clinical expression of the case depends on the extent and area of brain damage, growth of the child, coexisting developmental problems.
\end{abstract}

Volume 4 Issue I - 2016

\author{
Bari MM,' Shahidul Islam, ${ }^{2}$ Shetu $\mathrm{NH},{ }^{2}$ \\ Mahfuzer Rahman ${ }^{2}$ \\ 'Chief Consultant, Bari-llizarov Orthopaedic Centre,Visiting and \\ Honored Prof., Russian Ilizarov Scientific Centre, Russia \\ ${ }^{2}$ Bari-llizarov Orthopaedic Centre, Bangladesh
}

Correspondence: Mofakhkharul Bari, Chief Consultant, BariIlizarov Orthopaedic Centre,Visiting and Honored Professor, Russian Ilizarov Scientific Centre, Kurgan, Tel +88 01819211595 , Email bari.ilizarov3।@gmail.com

Received: December 16, 2015 | Published: January 04, 2016

\section{Introduction}

Cerebral palsy is a condition that affects thousands of babies and children each year. It is not contagious, which means no one can catch it from anyone who has it.

The word cerebral means having to do with the brain. The word palsy means a weakness or problem in the way a person moves or positions his or her body. A kid with Cerebral palsy (CP) has trouble controlling the muscles of the body (hall mark of the condition is motor dysfunction, i.e. there is abnormal muscle tone, abnormal posture and movement). ${ }^{1,2}$ Normally, the brain tells the rest of the body exactly what to do and when to do it. But because $\mathrm{CP}$ affects the brain, depending on what part of the brain is affected, a kid might not be able to walk, talk, eat or play the way most kids do.

It is a non-progressive but often changing motor impairment syndromes. It is usually secondary to an insult of limited duration or anomalies of the brain arising in the early stages of development. (Viz. prenatal, intranatal, neonatal and post natal up to 5 years). The changing clinical picture results from developmental maturation and intervention. The clinical expression of the case depends on the extent and area of brain damage, growth of the child, coexisting developmental problems.

\section{Sings and symptom}

Symptoms of cerebral palsy can be as simple as having difficulty with fine motor tasks like writing or using scissors or as profound as being unable to maintain balance or walk. Severely affected patients may have involuntary movements, such as uncontrollable hand motions and drooling. Others suffer from associated medical disorders, such as seizures, speech problem, hearing problem, language disorder, ocular problem (i.e. strabismus, refactory errors, field's defects), feeding difficulties, behavioral problems and mental retardation.

\section{Types of cerebral palsy (CP)}

Cerebral palsy can be classified as:
I. Physiological
a. Spastic
b. Dyskinetic (dystonic and athetoid)
c. Hypotonic
d. Ataxic
e. Mixed
II. Topographic
a. Quadri/tetraplegia
b. Hemiplegia
c. Diplegia
d. Monoplegia
e. Triplegia

\section{Spastic cerebral palsy (CP)}

Spastic cerebral palsy (CP) is the most common type of cerebral palsy. It causes the muscles to be stiff and permanently contracted. Spastic cerebral palsy is often sub classified as one of five types that describe the affected limbs. The names of these type combine a Latin prefix describing the number of affected limbs (e.g. di-means two) with the term plegia or paresis, meaning paralyzed or weak. ${ }^{3,4}$

\section{Diplegia: either both arms or both legs}

II. Hemiplegia: limbs on only one side of the body

III. Quadriplegia: all four limbs

IV. Monoplegia: one limb (extremely rare)

V. Triplegia: three limbs (extremely rare)

Spastic diplegia: Spastic diplegia affects the legs more than the arms. The legs often turn in and cross at the knees. This causes a scissors gait, in which the hips are flexed, the knees nearly touch, the feet are flexed and the ankles turn out from the leg, causing toe-walking. Learning disabilities and seizures are less common than in spastic hemiplegia.

Spastic hemiplegia: Persons with spastic hemiplegia (hemiparesis) also may experience hemiparetic tremors-uncontrollable shaking of the limbs on one side of the body. Severe hemiparetic tremors can 
seriously impair movement. The arm is generally affected more than the leg. Learning disabilities, vision problems, seizures and dysfunction of the muscles of the mouth and tongue are classic symptoms.

Spastic quadriplegia: Spastic quadriplegia involves all four limbs. There is dysfunction of the muscles of the mouth and tongue, seizures, medical complication and increased risk for cognitive difficulties.

Mixed CP: Mixed CP involves two or more types of cerebral palsy. While any mix of types and subtypes can occur, the most common are athetodic-spastic-diplegic and athetoid-spastic-hemiplegic; the least common is athetoid-ataxic. It is possible to have a mix of all three (spastic-athetoid-ataxic).

\section{Complication}

Some people with $\mathrm{CP}$ have associated disorders, such as impaired intellectual development, seizures, failure to grow and thrive and vision and sense of touch problems. Roughly a third of patients with $\mathrm{CP}$ also have mild intellectual impairment, another third are moderately or severely impaired and the remainder, intellectually normal. Mental impairment is most common in children with spastic quadriplegia.

\section{Diagnosis}

The diagnosis of CP is essentially involves detail history of prenatal, natal and postal history and careful physical and neurodevelopment examination to identify deficit type and topography, which is required for management. Early identification has significant implication for the family and necessitates early intervention to achieve the maximum holistic potential of the child. The philosophy behind early intervention is bases on the following facts: , $^{1,5,6}$

I. A neurological insult recovers better with stimulation.

II. I.Q. of emotionally deprived children is poorer than stimulated children.

III. The plasticity of the brain in the first decade of life provides a window of opportunity for active intervention.

IV. Actually a child with $\mathrm{CP}$ is not hopeless. Half of the child with $\mathrm{CP}$ have average or above I.Q.

V. With timely help and proper guidance a vast majority can lead active, self supporting and long lives.

VI. Thus early diagnosis is prerequisite.

\section{Evaluation}

The diagnosis of CP is essentially clinical. It involves a detail prenatal, natal and post natal history and careful physical and neurodevelopmental examination to identify deficit type and topography which is required for management.

\section{Investigation}

Laboratory test are not necessary to confirm diagnosis. Brain imaging studies including USG, CT and MRI may be useful in elucidating the etiology of $\mathrm{CP}$ and suggesting prognosis. Vision, auditory screening along with EEG should be done if patient is not improving after adequate physiotherapy.

\section{Materials and methods}

Since 1990 to till 2014, we treated 46 patients of different categories of CP. Outcome of the patients are satisfactory (Figure $1 \& 2$ ).

\section{Management}

It is multidisciplinary approach. ${ }^{7-9}$

I. Physical Therapy: Through this helps the child walking, sitting and keeping his/her balance. Also to prevent contracture.

II. Occupational therapy: Help the child develop fine motor skills such as dressing, feeding, writing and other daily living skills.

III. Speech therapy: To develop communication skill.

IV. Feeding problem: Initially start with soft, small frequent feed. Drooling can be minimized by improving swallowing. Drugs are not very effective.

V. Educational problem: Mild CP does well in mainstream schools. Moderate to severe CP need to be educated in special school.

VI. Communication: Discourage sign language and encourage speaking.

VII. Spasticity: If it does not improve with physiotherapy, then Botulinum Toxin Type-A injection can be given, which block release of acetylcholine from presynaptic terminal and blocks signal transmission at neuromuscular junction. It works for 3-5 months. Beclophen orally or intrathecal continuous pump can be implanted.

\section{Choice of surgery}

I. Operation on muscles and tendons

II. Tenotomy, tendon lengthening tendon transfers

III. Myotomy and muscle transposition

IV. Operation on bones and joints

V. Bone lengthening by Ilizarov technique

VI. Osteotomies to correct knock knee

VII. Arthrodesis of wrist, hip and foot to correct deformity

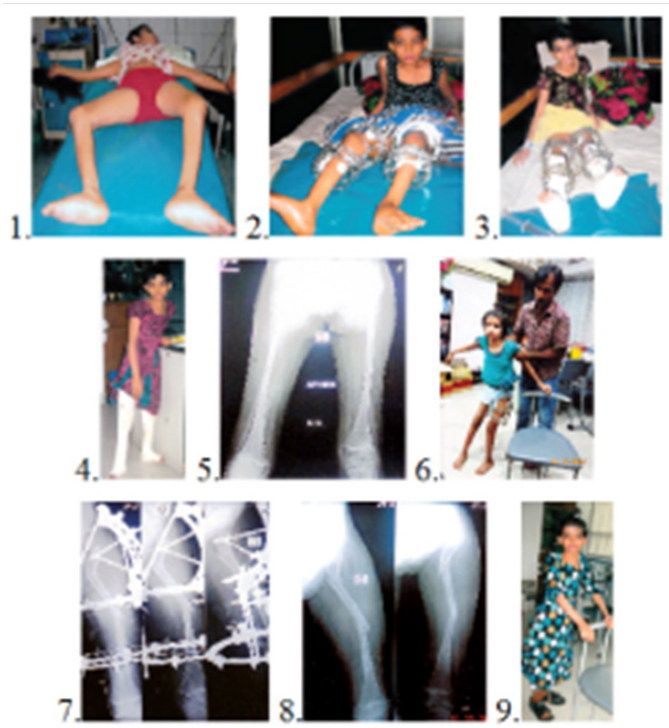

Figure I

I. 12 years old girl with bilateral knee flexion contracture with bilateral pes plano valgus. 
2. Correction of both knee flexion contracture with llizarov apparatus.

3. Grice operation was done in both ankle (Extra articular arthrodesis).

4. Patient is walking with plaster cast. Since birth she did not stand and walk.

5. Congenital left hip dislocation.

6. llizarov in the left hip and thigh.

7. X-ray of PSO (Pelvic Support Osteotomy).

8. After removal of Ilizarov apparatus

9. Patient is walking with KAFO.
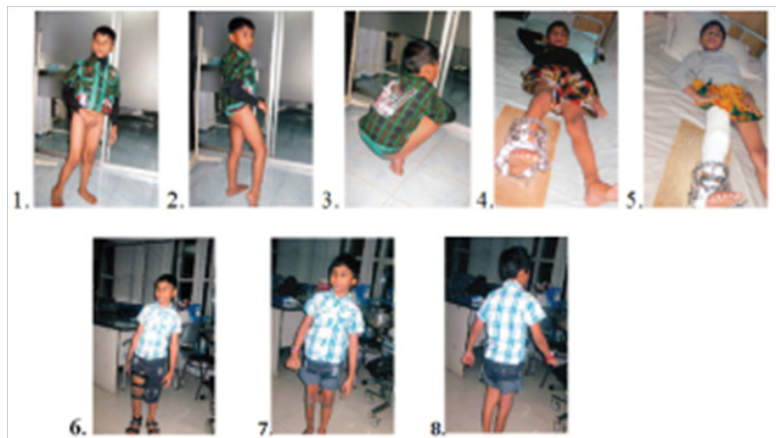

\section{Figure 2}

I. 9 years old boy - Right Pes Equinus $>650$

2. Right Pes Equinus $>650$ (Lateral view).

3. Cannot squat.

4. During treatment with llizarov.

5. Plaster immobilization in the knee with llizarov in the ankle.

6. With KAFO (knee ankle and foot orthosis).

7. Clinical appearance of the patient. Final follow up (Front view)

8. Clinical appearance of the patient. Final follow up (Back view).

\section{Aim of Surgery in CP}

I. To correct the deformity

II. To balance the muscle power

III. To stabilize uncontrollable joints

\section{Complication}

So early intervention is the key for improvement of CP, specially the first 2 years is most important. This is the time when brain is growing very fast. In simple word this is the express train. Try to catch it. If you miss it try to catch the local train, which is up to 5 years. Still it is better than something.

\section{Acknowledgments}

None.

\section{Conflicts of interest}

None.

\section{References}

1. Root L. Treatment of hip problems in cerebral palsy. Instr Course Lect. 1987;36:237-252.

2. Lonstein JE, Beck K. Hip dislocation and subluxation in cerebral palsy. J Pediatr Orthop. 1986;6(5):521-526.

3. Bleck EE. The hip in cerebral palsy. Orthop Clin North Am 1980;11(1):79-104.

4. Wood E, Rosenbaum P. The gross motor function classification system for cerebral palsy: a study of reliability and stability over time. Dev Med Child Neurol. 2000;42(5):292-296.

5. Robin J, Graham HK, Baker R, et al. A classification system for hip disease in cerebral palsy. Dev Med Child Neurol. 2009;51(3):183-192.

6. Jones DH. Shenton's line. J bone Joint Surg [Br] . 2010;92(9):1312-1315.

7. Persson-Bunke M, Hagglund G, Lauge-Pedersen H. Windswept hip deformity in children with cerebral palsy. $J$ Pediatr Orthop B. 2006;15(5):335-338.

8. Carr C, Gage JR. The fate of the nonoperated hip in cerebral palsy. $J$ Pediatr Orthop. 1987;7(3):262-267.

9. Bari MM. A color atlas of limb lengthening, surgical reconstruction and deformity correction by Ilizarov technique. 2013;pp.212-228. 